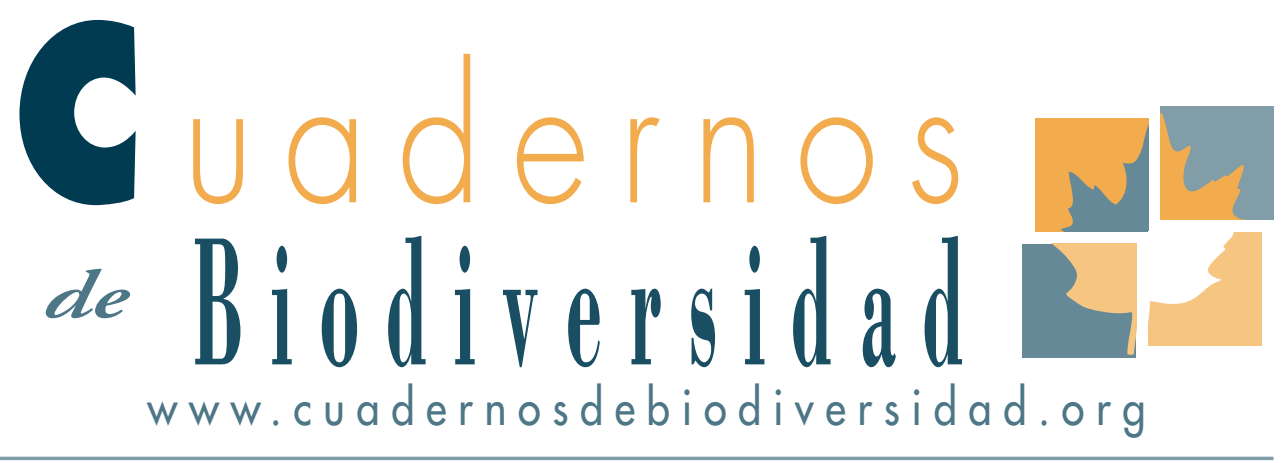

\title{
Crioconservación: herramienta para la conservación ex situ de material vegetal
}

\section{A. Marco-Medina, F. Serrano-Martínez}

INSTITUTO DE INVESTIGACIÓN CIBIO (CENTRO IBEROAMERICANO DE LA BIODIVERSIDAD). UNIVERSIDAD DE ALICANTE

F.SERRANO@UA.ES

\section{ABSTRACT}

Nowadays different in vitro techniques are employed in order to preserve plant species. Among these, cryopreservation (the conservation of plant material at ultralow temperature, usually at $-196^{\circ} \mathrm{C}$, which is the temperature of liquid nitrogen) is widely employed for long-term storage of plant germplasm. These techniques could complement other ex situ strategies like seed banks or field collections, and are the unique reliable way for long-term preservation of species that are vegetatively propagated or have recalcitrant seeds. Recently, cryopreservation protocols in Tetraclinis articulata and Thymus moroderi explants have been developed.

\section{KEY WORDS:}

In vitro conservation, cryopreservation, Thymus moroderi, Tetraclinis articulata, vitrification

\section{INTRODUCCIÓN}

Dentro de las diferentes estrategias existentes en la actualidad para la conservación ex situ de germoplasma vegetal encontramos las técnicas de cultivo in vitro, permitiendo conservarlo a corto, medio y largo plazo. Para la conservación a largo plazo, la técnica empleada es la crioconservación. Ésta se define como la preservación de células viables, tejidos y órganos a temperaturas ultrabajas, principalmente en nitrógeno líquido (NL), cuya temperatura es de $-196^{\circ} \mathrm{C}$. Este procedimiento de almacenamiento puede ser aplicado a un amplio rango de organismos y tejidos biológicos, y es considerado el método más estable de conservación de germoplasma, puesto que la actividad metabólica y muchos procesos físicos cesan a esa temperatura (PANIS \& LAMBARDI, 2005).

Dentro de la crioconservación, existen diferentes técnicas para llevarla a cabo, aunque en todas ellas lo que se persigue es evitar la formación de hielo intracelular, lo que supondría causar daños irreversibles 
en la membrana celular (PANIS \& LAMBARDI, 2005). En general, distinguimos las técnicas clásicas, basadas en la deshidratación inducida por la congelación (congelación lenta o por etapas) y las modernas, basadas en la vitrificación (ENGELMANN, 2000). El término vitrificación hace referencia a la transición de una solución acuosa desde líquido a un estado amorfo vítreo, evitando la formación de hielo (FAHY et al. 1984). Esto es seguido por la inmersión directa en NL. Se han descrito diferentes métodos de crioconservación basados en la vitrificación: encapsulación-desecación, vitrificación, encapsulación-vitrificación, desecación, precultivo, precultivo-desecación, congelación en gota (droplet freezing) y más recientemente la vitrificación en gota (droplet vitrification) (ENGELMANN, 2000).

En nuestro laboratorio hemos empleado las técnicas de vitrificación, encapsulación-desecación y vitrificación en gota para la crioconservación de especies vegetales endémicas y/o amenazadas, que describimos a continuación:

La técnica de vitrificación se basa en la exposición de los explantos a una solución de vitrificación altamente concentrada durante periodos de tiempo variables, seguida de inmersión directa en NL. Esto resulta en la vitrificación tanto intra- como extracelular. La solución de vitrificación más utilizada es la denominada PVS2 (Plant Vitrification Solution 2), descrita por SAKAI y colaboradores (1990) y que consiste en glicerol $30 \%$, etilenglicol $15 \%$, DMSO $15 \%$ y sacarosa $0.4 \mathrm{M}$. La vitrificación se ha convertido en el protocolo de crioconservación más utilizado, puesto que es fácil de llevar a cabo, altamente reproducible y puede aplicarse con éxito a un amplio rango de tejidos y especies vegetales (PANIS \& LAMBARDI, 2005).

En el método de encapsulación-desecación (FABRE \& DEREUDRE, 1990) los explantos (normalmente meristemos o embriones) se incluyen en cuentas de alginato, se exponen a altas concentraciones de sacarosa y seguidamente se desecan utilizando gel de sílice o el aire de la cabina de flujo laminar hasta reducir el contenido de humedad al 20-30\%, finalmente se sumergen las cuentas directamente en NL.
La vitrificación en gota (droplet vitrification) es una combinación de la congelación en gota y la vitrificación. Los explantos se deshidratan en una solución de vitrificación (PVS2 u otras), se disponen en pequeñas gotas sobre una hoja de papel de aluminio y a continuación se sumergen rápidamente en NL. Es una técnica más reciente y ha sido empleada con éxito en diversas especies (SAKAI \& ENGELMANN, 2007).

\section{DOS CASOS PRÁCTICOS: CRIOCON- SERVACIÓN DE THYMUS MORODERI Y TETRACLINIS ARTICULATA}

Thymus moroderi Pau ex Martínez es una especie endémica de las provincias españolas de Alicante y Murcia, empleada como aromatizador de un licor (cantueso) y en la medicina tradicional (sus infusos tienen propiedades digestivas). Esta especie figura como casi amenazada en la Lista Roja 2008 de la Flora Vascular Española (MORENO, 2008). Para su conservación se han desarrollado diferentes protocolos de crioconservación: vitrificación en gota (MARCO-MEDINA et al., 2010a), vitrificación y encapsulación-desecación (MARCO-MEDINA et al., 2010b).

Los mejores resultados se obtuvieron con la vitrificación en gota (hasta un $80 \%$ de supervivencia post-descongelación) (Fig. 1A,B,E) y la vitrificación (71\% de supervivencia post-descongelación) (Fig. 1D). Cabe destacar que la vitrificación en gota produjo mayores tasas de supervivencia empleando un tiempo de exposición a la PVS2 menor $(30 \mathrm{~min}$ ) que con la vitrificación (60 min). Estas técnicas son menos laboriosas que la encapsulación-desecación (Fig. 1C) y requieren un menor tiempo de deshidratación del material a crioconservar.

Por otro lado, cabe comentar que a la hora de desarrollar una estrategia de crioconservación es fundamental la recuperación del material tras la descongelación. En esta etapa post-descongelación, es frecuente la aparición de hiperhidratación, y en algunas ocasiones sólo se desarrolla callo puesto que parte del meristemo apical resulta dañado. En el caso 
de T. moroderi, en un ensayo preliminar realizado con explantos apicales se seleccionó el medio MS con $0.5 \mathrm{mg} \mathrm{l-1}$ de benziladenina (BA) para el crecimiento de los explantos tras la crioconservación. Sin embargo tras dos semanas ya se podían observar síntomas de hiperhidratación. Para revertir este proceso fisiológico probamos diferentes concentraciones de BA, seleccionando finalmente para la regeneración de los explantos crioconservados el medio MS suplementado con $0.05 \mathrm{mg} \mathrm{l-1} \mathrm{BA} \mathrm{(Fig.} \mathrm{1A-B).}$ Esta citoquinina produce hiperhidratación en $T$. moroderi, por lo que tras tres semanas se recomienda transferir los explantos a medio sin reguladores.

Aunque los diferentes experimentos de encapsulación-desecación realizados no consiguieron mejorar los resultados obtenidos con las otras dos técnicas, pudimos comprobar la influencia positiva de la aclimatación de los explantos al frío en la supervivencia tras la congelación. Cuando las plantas son sometidas a estrés por bajas temperaturas, se induce la expresión de numerosos genes (OUFIR et al., 2008) y se producen una serie de cambios en la estructura de la membrana, en la composición celular y en la pared celular (CHANG et al., 2000) que, en conjunto, pueden determinar la adaptación a las bajas temperaturas.

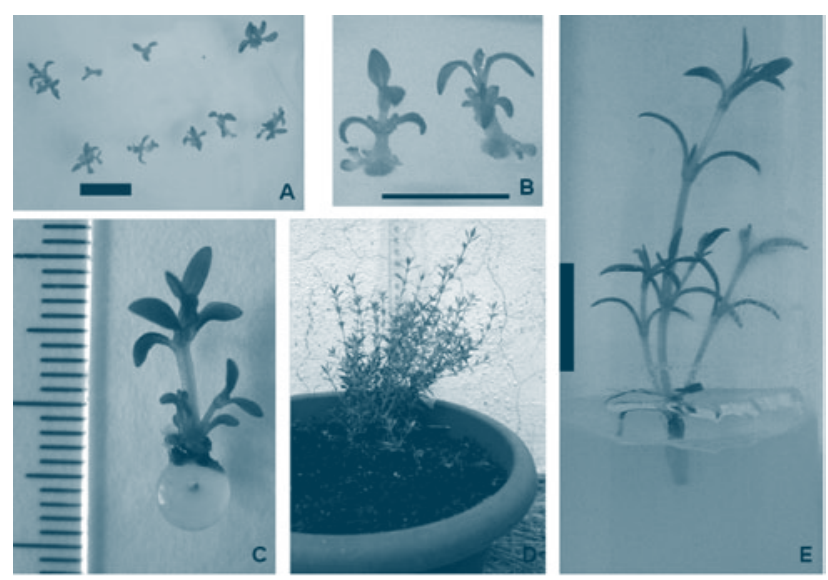

Fig 1. Ápices crioconservados creciendo en medio con $0.05 \mathrm{mg} \mathrm{l-1} \mathrm{BA,} \mathrm{tres} \mathrm{semanas} \mathrm{tras} \mathrm{la} \mathrm{descongelación} \mathrm{(A-}$ B). Explanto tras la encapsulación (C). Planta aclimatada procedente de un ápice crioconservado por vitrificación, 5 meses después del inicio de la aclimatación (D). Explanto superviviente a la vitrificación en gota, dos meses después de la descongelación (E). Barra $=1 \mathrm{~cm}$.
Otra de las especies en la que se ha elaborado un protocolo de crioconservación en nuestro laboratorio es Tetraclinis articulata (Vahl) Masters (Fig. 2A), una conífera perteneciente a la familia Cupressaceae que tiene un alto interés etnobotánico y biogeográfico. Además, su madera ha sido empleada con diferentes fines, tales como combustible, medicina tradicional y artesanía. Sin embargo, el principal motivo por el que desarrollamos diferentes técnicas de cultivo in vitro para esta especie es que se encuentra catalogada en la Lista Roja 2008 de la Flora Vascular Española (MORENO, 2008) como vulnerable de acuerdo a las categorías UICN.

La crioconservación de esta especie se realizó mediante vitrificación, empleando como material ápices de $1 \mathrm{~mm}$ de longitud (SERRANO-MARTÍNEZ \& CASAS, 2011). La crioconservación de esta especie presentó una elevada dificultad puesto que los ápices (Fig. 2B) resultaron altamente sensibles a la aplicación de las diferentes soluciones empleadas en los sucesivos pasos del proceso de crioconservación (carga en una solución concentrada de sacarosa $(0.4 \mathrm{M})$ y glicerol $(2 \mathrm{M})$ durante $20 \mathrm{~min}$, deshidratación en PVS2 a distintos tiempos y descarga en una solución de sacarosa $(1,2 \mathrm{M})$ durante $10 \mathrm{~min}$; todas ellas en medio $\mathrm{SH}$ ), ya que se observaba una alta mortalidad incluso sin la inmersión en NL y aplicando solo las soluciones de carga y descarga. Esto hizo que fuese necesario variar la composición inicial de las soluciones para tratar de mejorar los resultados. Para ello, se sustituyó la sacarosa por sorbitol a la misma concentración molar, mejorando así el porcentaje de ápices supervivientes a la aplicación de las soluciones pero no a la congelación en NL. Este último problema se solventó aclimatando previamente en frío $\left(4^{\circ} \mathrm{C}\right.$ o $\left.10^{\circ} \mathrm{C}\right)$ los explantos de donde se obtenían los ápices para la crioconservación. Gracias a este paso, se consiguió una tasa relativamente alta de supervivencia post-descongelación (35.41\%) (Fig. 2C). Al igual que en la aplicación de la técnica de encapsulación-desecación en $T$. moroderi, la aclimatación al frío resultó beneficiosa a la hora de incrementar las tasas de supervivencia post-descongelación del material. 

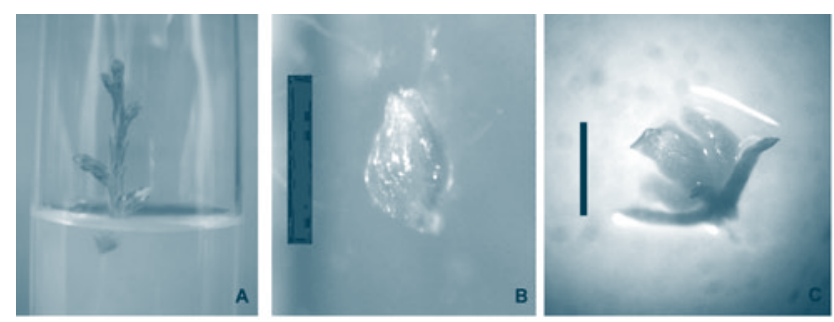

Fig 2. Explanto de Tetraclinis articulata (A). Ápice escindido previamente a la crioconservación (B). Ápice superviviente a la descongelación $(C)$. Barra $=1 \mathrm{~mm}$.

\section{CONCLUSIÓN}

La crioconservación es una herramienta de conservación ex situ que se emplea con éxito en numerosas especies vegetales tanto de interés agrícola como amenazadas. Existen diversas técnicas para poder llevarla a cabo tales como la vitrificación, encapsulación-desecación o vitrificación en gota entre otras. La selección de una técnica en concreto dependerá de cada especie. Además, es incluso necesario, optimizar para cada genotipo las diferentes etapas que comprende el protocolo de crioconservación (precultivo, deshidratación, congelación, descongelación...) con el fin de obtener una alta tasa de recuperación post-descongelación. También cabe comentar que la aclimatación al frío puede resultar una estrategia útil para mejorar la respuesta del material a la crioconservación, tal y como hemos podido comprobar en T. moroderi y T. articulata.

\section{REFERENCIAS}

CHANG, Y., BARKER, R.E. \& B.M. REED.2000. Cold acclimation improves recovery of cryopreserved grass (Zoysia and Lolium sp.). CryoLetters 21:107-116.

ENGELMANN, F. 2000. Importance of cryopreservation for the conservation of plant genetic resources. En: Engelmann, F. \& H. Takagi (Eds.), Cryopreservation of Tropical Plant Germplasm. Current Research Progress and Application, IPGRI, Rome, Italy. Pp 8-20.
FABRE, J. \& J. DEREUDRE (1990) Encapsulation-dehydration: a new approach to cryopreservation of Solanum shoot tips. CryoLetters 11:413-426.

FAHY, G.M., MACFARLENE, D.R., ANGELL, C.A. \& H.T. MERYMAN. 1984. Vitrification as an approach to cryopreservation. Cryobiology 21: 407-426.

MARCO-MEDINA, A., J. L. CASAS, R. SWENNEN \& B. PANIS. 2010a. Cryopreservation of Thymus moroderi by droplet vitrification. CryoLetters 31:14-23.

MARCO-MEDINA, A., J.L. CASAS \& M. E. GONZÁLEZ-BENITO. 2010b. Comparison of vitrification and encapsulation-dehydrationfor cryopreservation of Thymus moroderi shoot tips. CryoLetters 31:301-309.

MORENO, J. C. (coord.). 2008. Lista Roja 2008 de la flora vascular española. Dirección General de Medio Natural y Política Forestal (Ministerio de Medio Ambiente, y Medio Rural y Marino, y Sociedad Española de Biología de la Conservación de Plantas), Madrid, 86 pp.

OUFIR, M., LEGAY, S., NICOT, N., VAN MOER, K., HOFFMANN, L., RENAUT, J., HAUSMAN, J.F. \& D. EVERS. 2008. Gene expression in potato during cold exposure: Changes in carbohydrate and polyamine metabolisms. Plant Science 175:839-852.

PANIS, B. \& M. LAMBARDI. 2005. Status of cryopreservation technologies in plants (crops and forest trees). En: Ruane, J. \& A. Sonnino (Eds.), The role of biotechnology for the characterization and conservation of crop, forest, animal and fishery genetic resources in developing countries. Turin: FAO. Pp. 61-78.

SAKAI, A., KOBAYASHI, S. \& I. PIYAMA. 1990. Cryopreservation of nucellar cells of navel orange (Citrus sinensis Osb. var. Brasiliensis Tanaka) by vitrification. Plant Cell Reports 9:30-33.

SAKAI, A. \& F. ENGELMANN. 2007. Vitrification, encapsulation-vitrification and droplet-vitrification: a review. CryoLetters 28:151-172.

SERRANO-MARTÍNEZ, F. \& J.L. CASAS. 2011. Cryopreservation of Tetraclinis articulata (Vahl.) Masters. CryoLetters 32:248-255. 